\title{
A new Atrococcus species (Hemiptera, Coccomorpha, Pseudococcidae) from China, with a key to Chinese species
}

\author{
Jiang-Tao Zhang ${ }^{1,2}$, Jia-Ying Zhou ${ }^{1,2}$, You-Liang Pan ${ }^{1,2}$, Xing-Ping Liu ${ }^{1,2}$ \\ I College of Forestry, Jiangxi Agricultural University, Nanchang 330045, China 2 Key Laboratory of National \\ Forestry and Grassland Administration for the Protection and Restoration of Forest Ecosystem in Poyang Lake \\ Basin, Nanchang 330045, China \\ Corresponding author: Jiang-Tao Zhang (jiang_tao_zhang@163.com) \\ Academic editor: G. Goemans | Received 11 December 2019 | Accepted 6 May 2020 | Published 20 July 2020 \\ http://zoobank.org/41E6BCB6-0976-41E2-AF41-AC51C1B5A450 \\ Citation: Zhang J-T, Zhou J-Y, Pan Y-L, Liu X-P (2020) A new Atrococcus species (Hemiptera, Coccomorpha, \\ Pseudococcidae) from China, with a key to Chinese species. ZooKeys 950: 33-40. https://doi.org/10.3897/ \\ zookeys. 950.49300
}

\begin{abstract}
A new mealybug species Atrococcus rushuiensis Zhang, sp. nov., collected under the leaf sheath of Sporobolus fertilis (Poaceae) in Fuzhou City, Jiangxi Province, China, is described and illustrated. A new combination is introduced, transferring Allotrionymus shanxiensis Wu to the genus Atrococcus as A. shanxiensis (Wu), comb. nov. A key is presented for the species of Atrococcus recorded from China.
\end{abstract}

\section{Keywords}

Atrococcus rushuiensis, Jiangxi, mealybug, new combination, Sporobolus fertilis, taxonomy

\section{Introduction}

The genus Atrococcus Goux, 1941 (Pseudococcidae, Pseudococcinae) was established with Atrococcus melanovirens Goux as its type species. With oral rim ducts present, Atrococcus is morphologically similar to Allotrionymus Takahashi, Chorizococcus McKenzie, Spilococcus Ferris, and Vryburgia De Lotto (Wu 2000). Due to the inadequate definition, different authors have applied different combinations of characters for generic separation (e.g., Williams 1962; Tang 1992; Danzig and Gavrilov-Zimin 2015).

Copyright Jiang-Tao Zhang et al. This is an open access article distributed under the terms of the Creative Commons Attribution License (CC BY 4.0), which permits unrestricted use, distribution, and reproduction in any medium, provided the original author and source are credited. 
Based on a study of mealybugs from Russia and neighbouring countries, Danzig and Gavrilov-Zimin (2015) found that there is no difference between Allotrionymus and Atrococcus, and treated Allotrionymus as a junior synonym of Atrococcus. Hence, we follow Danzig and Gavrilov-Zimin (2015) in regarding Allotrionymus as a junior synonym of Atrococcus.

In China, Tang and Li (1988) first recorded Atrococcus from Inner Mongolia and reported three species: $A$. achilleae (Kiritchenko) (on the root of Bassia scoparia), A. innermongolicus Tang in Tang and $\mathrm{Li}$ (on the root of Artemisia apiacea) and A. paludinus (Green) (on Leppula intermedia). Later, Tang (1992) recorded two Allotrionymus species: Al. elongatus Takahashi (on Heteropappus altaicus) and Al. multipori Kawai (on Chloris radiata) from Inner Mongolia; the former was a misidentification of Chorizococcus scorzonerae Tang found by Wu (2000). Meanwhile, Tang (1992) also transferred Spilococcus pacificus (Borchsenius) to Atrococcus and Trionymus plurostiolatus Borchsenius to Allotrionymus. The above-mentioned four species were placed under Atrococcus by Danzig and Gavrilov-Zimin (2015). Subsequently, Wu (1999) described a new species Allotrionymus calamagrostis Wu (under the leaf sheath of Calamagrostis sp.) from Henan; this species was placed in the genus Atrococcus by Danzig and Gavrilov-Zimin (2015). Recently, Wu (2000) provided a study of Atrococcus and its related genera, reporting a new species, Allotrionymus shanxiensis Wu (under the leaf sheath of Melica scabrosa) from Shanxi, which is transferred to Atrococcus as A. shanxiensis comb. nov. following the present generic diagnosis. Wu (2000) also reported a new Chinese record, A cracens Williams, collected from Inner Mongolia (on Artemisia halodendron?) and Shanxi (on Artemisia sp. and Heteropappus altaicus). Including the new species described here, there are ten Atrococcus species recorded in China: $A$. achilleae, $A$. calamagrostis, A. cracens, $A$. innermongolicus, A. multipori, A. pacificus, A. paludinus, A. plurostiolatus, A. rushuiensis sp. nov., and A. shanxiensis comb. nov.

In this study, a new species, $A$. rushuiensis Zhang, sp. nov., is described from China, and a key to the Chinese Atrococcus species is also provided.

\section{Materials and methods}

All mealybug specimens were collected from under the leaf sheaths and transferred into $75 \%$ alcohol, then prepared and mounted mainly according to the method of Borchsenius (1950). The terminology for the morphological features used in the description are mainly explained by Williams $(1962,2004)$. Photograph was taken with a Nikon D7500 camera. The descriptions and measurements were made using a light microscope (SOPTOP BH200) fitted with an ocular micrometre, and six slide-mounted specimens were studied for measurements. Measurements are in micrometres $(\mu \mathrm{m})$ except the lengths and widths of the bodies are given in millimetres $(\mathrm{mm})$; all measurements are given as minimum and maximum. Drawings are presented as is usual for Coccomorpha, with the central drawing showing the outline of the body and the dis- 
tribution of characters (dorsum on the left side, venter on the right), with the enlarged details (not to scale) showing the structure of important characters around the margin.

All specimens examined are deposited in the College of Forestry, Jiangxi Agricultural University, Jiangxi, China.

\section{Taxonomy}

\section{Atrococcus Goux, 1941}

Pseudococcus (Atrococcus) Goux, 1941: 69. Type species: Atrococcus melanovirens Goux by original designation.

Generic diagnosis. Body in life usually greenish or white, females of some species show black coloration after being placed in ethanol or potash. Body of adult female on slide oval to elongate oval. Antennae seven- or eight-segmented. Circulus present or absent. Legs well developed, claw without a denticle. Both pairs of ostioles well developed. Anal ring usually situated at apex of abdomen, bearing six setae. Anal lobes moderately developed, each bearing a normal apical seta. Cerarii numbering 1-17 pairs, each cerarius usually bearing two conical setae. Trilocular pores numerous, evenly scattered on all body surface. Multilocular disc pores usually present on venter, more rarely present on dorsum. Oral rim ducts present, forming transverse rows on dorsum and sometimes present on venter. Oral collar tubular ducts present, at least on venter, sometimes present on dorsum. Most species have group of oral collar tubular ducts on prothorax in front of anterior spiracles, often accompanied by a group of multilocular disc pores. Flagellate setae of different sizes present on both body surfaces (adapted from Tang 1992, Danzig and Gavrilov-Zimin 2015).

\section{Atrococcus rushuiensis Zhang, sp. nov.} http://zoobank.org/FB9C2A23-2BA9-4646-879B-0423B1B92B6B Figures 1, 2

Material studied. Holotype. $\rightarrow$ (mounted singly on a slide), CHINA, Jiangxi Province, Fuzhou City, Rushui Forest Park [275' of Sporobolus fertilis (Poaceae), 2.x.2019, coll. Jiang-Tao Zhang. Paratypes. 8 우 (mounted on 8 slides), same data as holotype.

Etymology. The species name is based on the collection locality, Rushui Forest Park.

Description. Alive: body elongate, dark reddish, with thin covering of white mealy wax, and only caudal filaments present (Fig. 1).

Slide-mounted specimens $(N=6)$ : body of adult female (Fig. 2) elongate, 2.5$3.1 \mathrm{~mm}$ long, 0.9-1.4 mm wide. Anal lobes moderately developed, ventral surface of each lobe bearing an apical seta, each 100-122.5 $\mu \mathrm{m}$ long. Antennae eight-segmented, 


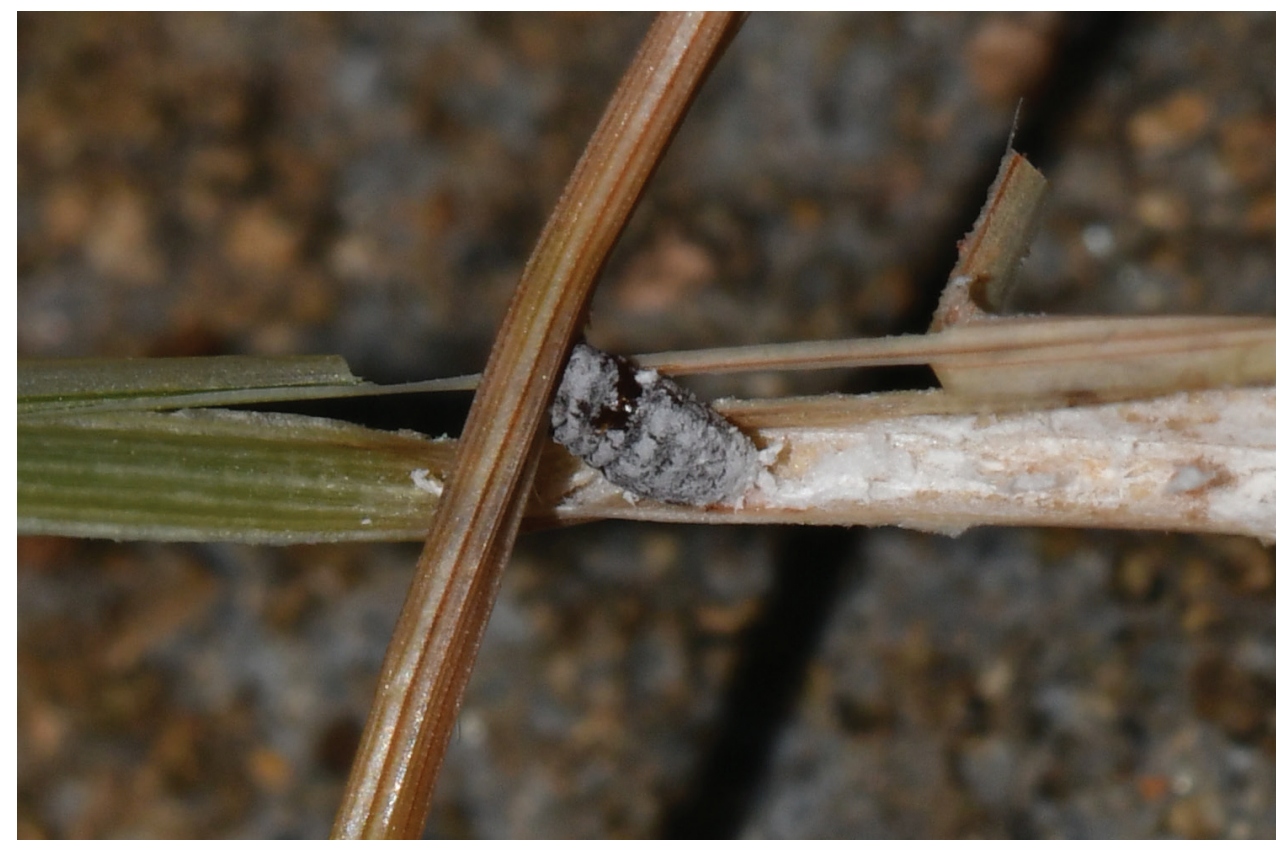

Figure I. Habitus photograph of Atrococcus rushuiensis sp. nov. under the leaf sheath of Sporobolus fertilis (Poaceae).

267.5-289 $\mu \mathrm{m}$ long, lengths of each segment: I 42.5-52.5, II 37.5-38.8, III 23.8-27.5, IV 18.8-22.5, V 17.5-23.8, VI 20-26.3, VII 28.8-32.5 and VIII 65-76.3 $\mu \mathrm{m}$. Eye spot located at body margin lateral to antennal base. Legs well developed; hind coxa 52.5-65 $\mu \mathrm{m}$ long, hind trochanter + femur 185-215 $\mu \mathrm{m}$ long, hind tibia + tarsus 198.8$240 \mu \mathrm{m}$ long; claw 17.5-22.5 $\mu \mathrm{m}$ long, both tarsal digitules and claw digitules knobbed, longer than claw. Ratio of lengths of hind tibia + tarsus to hind trochanter + femur 1.071.14:1. Ratio of lengths of hind tibia to tarsus 1.49-1.69:1. Translucent pores present, minute duct-like, present on anterior and posterior surface of hind coxa. Circulus absent. Clypeolabral shield 125-145 $\mu \mathrm{m}$ long. Labium with three segments, 62.5-70 $\mu \mathrm{m}$ long. Ostioles moderately developed, each lip with 4-13 trilocular pores and 0-2 short setae. Anal ring normal, 61.3-70 $\mu \mathrm{m}$ in diameter, bearing six long setae, each seta $82.5-103.8$ $\mu \mathrm{m}$ long. Cerarii numbering a single pair on anal lobes only. Anal lobe cerarii $\left(\mathrm{C}_{18}\right)$ each containing two slender conical setae, each seta 18-21 $\mu \mathrm{m}$ long, with 2-3 auxiliary setae, and 4-5 trilocular pores near conical setae base, all situated on a membranous area.

Dorsum. Setae short and slender, each 15-25 $\mu \mathrm{m}$ long. Trilocular pores each $3.5 \mu \mathrm{m}$ in diameter, evenly distributed. Oral rim ducts each 9-10 $\mu \mathrm{m}$ long, $6 \mu \mathrm{m}$ wide, in more or less single transverse rows on most segments. Oral collar tubular ducts absent or present, if present, each 6-7 $\mu \mathrm{m}$ long, $3 \mu \mathrm{m}$ wide, having fewer numbers marginally on abdominal segments VI or VII. Multilocular disc pores each $7-8 \mu \mathrm{m}$ in diameter, forming transverse rows or scattered on medial abdominal segments V-VII (V has $0-7$ pores, VI has $1-7$ pores, VII has 3-12 pores), occasionally few present on margin of abdominal segments V-VII. Discoidal pores minute, scattered. 


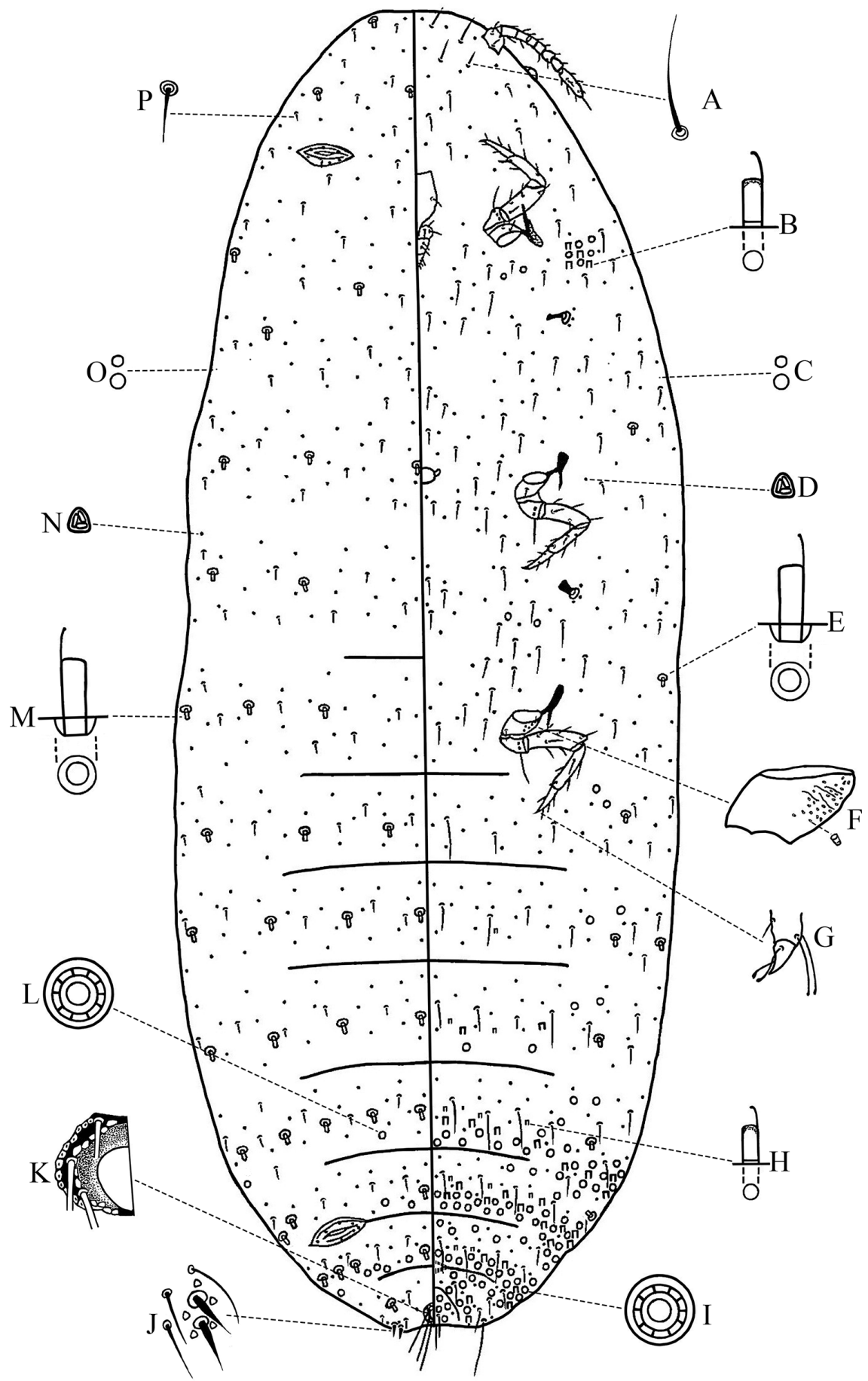

Figure 2. Adult female of Atrococcus rushuiensis sp. nov. Venter (A-I) A flagellate seta B large type of oral collar tubular duct $\mathbf{C}$ disc pore $\mathbf{D}$ trilocular pore $\mathbf{E}$ oral rim duct $\mathbf{F}$ hind coxa $\mathbf{G}$ claw $\mathbf{H}$ small type of oral collar tubular duct I multilocular disc pore. Dorsum (J-P) J anal lobe cerarius $\mathbf{K}$ anal ring $\mathbf{L}$ multilocular disc pore $\mathbf{M}$ oral rim duct $\mathbf{N}$ trilocular pore $\mathbf{O}$ disc pore $\mathbf{P}$ dorsal seta. 
Venter. Setae slender, longer than those on dorsum, each 36.3-80 $\mu \mathrm{m}$ long. Trilocular pores similar to those on dorsum, evenly distributed. Oral rim ducts same as those on dorsum, present on margin and submargin areas of thoracic and abdominal segments. Oral collar tubular ducts of two types: a large type, similar to those on dorsum, present in transverse rows across abdominal segments III-VIII or IV-VIII, also in marginal groups on abdominal segments V-VIII or VI-VIII, and a small group (together with multilocular disc pores) present on prothorax in front of anterior spiracles (4-11 ducts and 6-17 pores); a small type, each $5 \mu \mathrm{m}$ long, $2 \mu \mathrm{m}$ wide, mainly distributed across middle areas of abdominal segments III-VIII or IV-VIII, a few also present on margin with large ducts. Multilocular disc pores same as those on dorsum, numerous, present posterior to vulva, in transverse rows at posterior edges of abdominal segments IV-VII, in transverse rows at anterior edges of abdominal segments VI-VII, a few occurring on submargin areas of abdominal segments II-IV near oral rim ducts, also forming groups along margin of abdominal segments V-VIII or VI-VIII. Discoidal pores minute, scattered.

Host plant. Poaceae: Sporobolus fertilis.

Distribution. China: Jiangxi (Fuzhou).

Biology. Living under the leaf sheath of its host plant.

Remarks. Atrococcus rushuiensis sp. nov. is very similar to A. luffi (Newstead) in the number of cerarii and multilocular disc pores present on both body sides, but it differs from the latter by the following features (condition of $A$. luffi given in parenthesis): (i) dorsal margin oral collar tubular ducts absent or few (numerous, with multilocular disc pores in submarginal groups up to segment III); (ii) ventral oral rim ducts absent in median areas of prothorax and mesothorax (present in these areas); (iii) translucent pores duct-like (normal, not duct-like) [The morphology of $A$. luffi is mainly based on Williams (1962)].

The new species also resembles $A$. paludinus in possessing fewer than 20 oral rim ducts on each segment, which is different from $A$. luffi in having about 20 oral rim ducts on each segment, but differs from the latter by the following features (condition of $A$. paludinus given in parentheses): (i) cerarii numbering one pair only (cerarii numbering 6-7 pairs); (ii) Translucent pores duct-like (normal, not duct-like) [The morphology of $A$. paludinus is also mainly based on Williams (1962)].

In $A$. rushuiensis sp. nov., the number of ducts and pores vary among individuals, which belong to intraspecific variation. Some specimens have only a small number of ducts and pores, but in other specimens those ducts and pores are much more numerous.

\section{Key to adult females of Atrococcus known from China}

$1 \quad$ Multilocular disc pores present on venter and dorsum ..............................2

- Multilocular disc pores present on venter only .....................................5

2 Dorsal tubular ducts absent or present in compact groups along abdominal

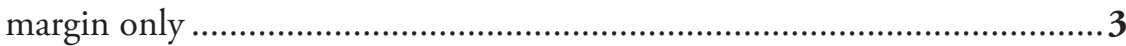

- Dorsal tubular ducts present and forming transverse rows 

Cerarii 6-7 pairs, dorsal multilocular disc pores on margins only of posterior abdominal segments.

A. paludinus (Green)

- $\quad$ Cerarii 3-4 pairs, noticeable groups of multilocular disc pores in submedian areas of dorsum A. cracens Williams

5 Circuli present 6

- $\quad$ Circuli absent A. innermongolicus Tang in Tang and $\mathrm{Li}$

Translucent pores normal, also extend to metathorax cuticle near hind coxae.

A. calamagrostis $(\mathrm{Wu})$

- Translucent pores duct-like, only present on the cuticle of hind coxae A. shanxiensis (Wu) comb. nov.

\section{Acknowledgements}

The project was supported by the Youth Science Foundation of Jiangxi Provincial Department of Education, China (GJJ180221).

\section{References}

Borchsenius NS (1950) Mealybugs and Scale Insects of USSR (Coccoidea). Akademii Nauk SSSR, Zoological Institute, Moscow, $250 \mathrm{pp}$.

Danzig EM, Gavrilov-Zimin IA (2015) Fauna of Russia and neighbouring countries. Palaearctic mealybugs (Homoptera: Coccinea: Pseudococcidae): subfamily Phenacoccinae (Part II). St. Petersburg, ZIN RAS, 619 pp. https://doi.org/10.31610/zsr/2015.24.2.236

Goux L (1941) Contribution a l'étude d'un faisceau d'espèces constituant un sous-genre nouveau du genre Pseudococcus (Hem. Coccidae). (Notes sur les coccides (Hem.) de la France, $29^{\text {eme }}$ note). Bulletin du Muséum d'Histoire Naturelle de Marseille 1: 66-83.

Tang FT, Li J (1988) Observations on the Coccoidea of Inner Mongolia in China. Inner Mongolia University Press, Inner Mongolia, $227 \mathrm{pp}$.

Tang FD (1992) The Pseudococcidae of China. Chinese Agricultural Science Technology Press, Beijing, 768 pp.

Williams DJ (1962) The British Pseudococcidae (Homoptera: Coccoidea). Bulletin of the British Museum 12(1): 1-79. https://doi.org/10.5962/bhl.part.5872

Williams DJ (2004) Mealybugs of Southern Asia. The Natural History Museum, London, $896 \mathrm{pp}$. 
Wu SA (1999) Descriptions of six new species of the family Pseudococcidae from Henan Province (Homoptera: Coccoidea). The Fauna and Taxonomy of Insects in Henan (Vol. 4). Insects of the Mountains Funiu and Dabie Regions. China Agricultural Scientech Press, Beijing, 415 pp.

Wu SA (2000) Atrococcus Goux and related genera of China (Hemiptera: Coccoidea: Pseudococcidae). Acta Zootaxonomica Sinica 25(2): 162-170. https://doi.org/10.3969/j. issn. 1000-0739.2000.02.009 